\section{六 提前墙合腾利原因}

此次提前堵合勝利之主要因素, 有以下三者:

(甲)上級黨與政府正確領導及争取提前合龍 方針之正確: 上級領導譏關自中央到地方，始終未

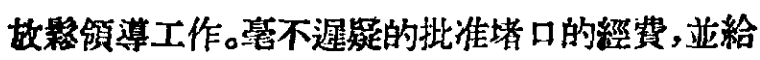
予各璉堵筑指示, 調墢各種料物器材。菲東及山東 省政府，在中央經資未报到前，提前熱借互款，以 便借料。各兄弟画，亦克分協助，不遺餘力。此次料 物動員，南達渴漢北及北京、天津、東北，西到開封， 東到青島, 造是國民黨與蔣政附時代所不能作到 的。ll東政府堅定不移的一再指示與鼓啀，因之不 諭堵策方圷上有何分枝意見，不論計劃如何變更， 最後則均䟽一到此一方針，並遵循此方針，具體組 轺與行動。

（乙）幹部工人之積政努力與帶頭：此次堵口 工程中,所有幹部工人,都爭先恐後, 參加工作。在

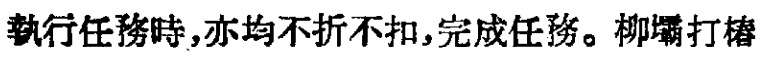
之工程隊員，在早晨少有薄冰的天氧赛，整日泡在
黄水中，起了帶䫓推動作用。口阿渡河民:士.下

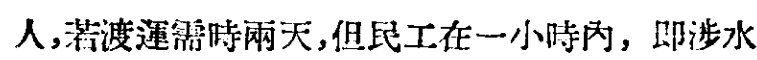
渡過，如無高度積極性，難有這樣数人的事䟖。電 嬁工人在電機浑到三小時之內, 就能阴澄。過河電 話䋐斷折,工人不避危險, 在夜間立刻接上，總尘

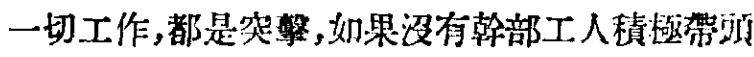
與推動,則桃沉前合龍,算在是不可能的。

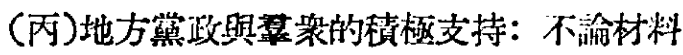
與人工慗啥有啥,源源供給, 保證了供應。地工镇 極性, 也異乎潯常, 不諭運料挑土都是快步湔進, 而且挑的筐很渶。有很多人挑拾筐, 趾經勤占, 仍 有不少人堅持,所以工作效茶,空前提宫。

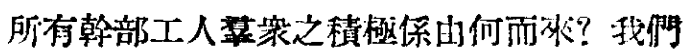
認篇是四年來人民治黄成果的具嗄表現。更重要

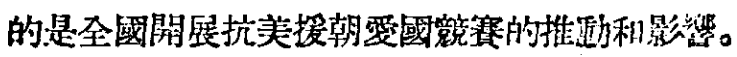

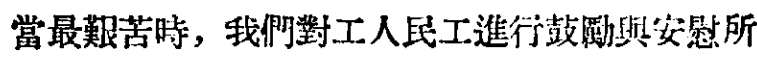
得的回答是: “志願軍在朝鮮比我們還萿，我们要 在堵口立功。”

（山東黄河河務局涌訊組）

\title{
組織療法的試驗報導
}

S內科椟生異常的耀耀着他的眼睛, 以最快的 速度,讀完了一篇文章的鉛字，之後他忽然做着深 呼吸,沉默的想了一會。原來他在第11期的“前進” 雜誌中,知道了蘇聯醫蛽革命, 冾藏植皮療法(即 䢸織療法)的令人第巽的報䓕文草，遭件事乃惹起 了他的十二分的注意。

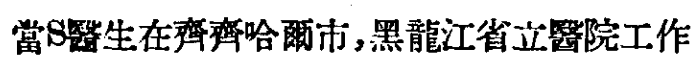

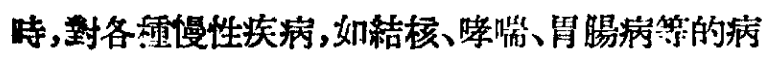

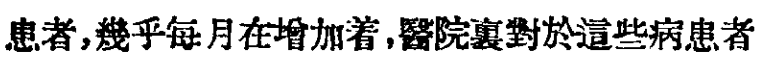
是繁资苦心的。踓然每年都有激的療法發表了，而 探用之後, 結果却均不能滿足的。如宣傳得很厲害 的鍕徽素, 說是結核病的特效葯, 可是費用既昂, 效用也不一定有把暒, 總不是理想的䒬物。而且患 病者，還需要長期休秦的抵抗奖病的耐心，時常使 人感到煩閔。㽞生們也感到慢性病與急性病有些 不同,病情的侅化很少，致治療病人的工作情緒， 也就低柾了。他自知道有組織潦法之後, 是是喜出 望外，像在沙漠中弡現称洲似的喜㤝。

第二天一起早, 他立即拿着那一期的“前進”
新誌去與醫院院長洽談, 而且常面提出了要進行

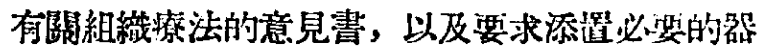
材的請求書,他馬上得到院長的同意和嵮㢦，他一

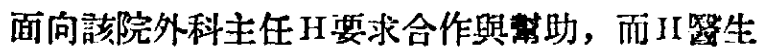

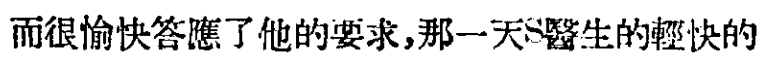
心情是難以想像的。

在中國报起全國規模的抗美搝朝，展䍀生流 競賽運動之後，這侗醫院寒的日本人學望小組,在 這偉大運動的賞中，S 醫生也以普遍推行組䋘潦

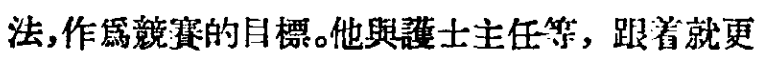
深入了病房, 將㑤萑聯專家所發明的療法, 而且在日 本,已由日共所領導的醫院,在廣泛的嫄用着, 亚

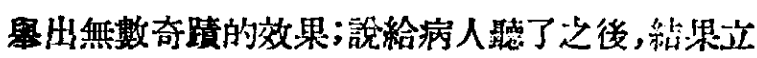
刻有三名患者同意接受這個澵的塐法，一、二、三、 日內就有十數名欣然接受道储療法了, 每個病人 都要求S醫生早日施行逜個療法。

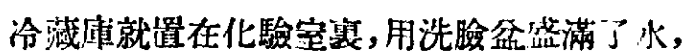
在室外放了一夜,就凍成冰了，(這是指冬委加猝 哈爾市而言,譯者噇)，冾藏㡷內保持捧氏三度左
- 880 •
科學通報
第二受 
右。包蓝創口的銀紙以及其他器材都由院長自己

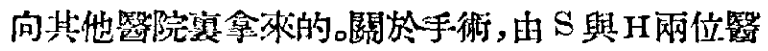
生,經過詳細商議的。

一位病人在那毫等待不酎煩, 不斷的要求立 即進行手術。

\section{“多些給我們手街”}

他答道; “先由我們把自己試駿以後，給你們 做”

“不用試, 就閐始吧”。急不及待的, 連自己試 驗的工夫也來不及, 在 $\mathbf{1 2}$ 月 26 日就有四名病人接 受手術了。

賞你從洞清過的白布下面凝悓著病人懷着希

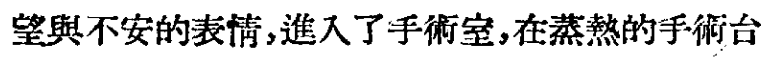
上的時候，㕷生向病人緊緊的握了手，而安慰的 說: “你放心吧”，一面微笑着一面點着頭，……剝 皮手術就輕易的成功了。手術後, 也汥有什麼痛苦 的經過了三日.一直等到植皮手術的這一天。輕輕 的在創口上去了銀紙之後, 創口上的組織液汁, 凍

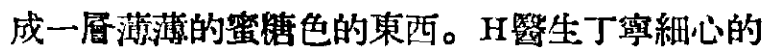
把以上的東西揩拭了去, 將冷藏過的稍帶皱摺的

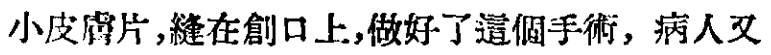
琈現輕快和安心的表情。

踓然所有的手術都做得很順利, 可是 $\mathrm{S}$ 醫生 也不等到第二天天亮, 在當天淿登之前, 就到病房 裹巡涀了一番。有一位哮喘病人已感學到病况好 轉, 就老䁈的回答S的問話: “我覺得好一點兒了”。

第二天早晨,S比平常醒得更早，草草的洗了 脸, 就去病房。那位嫖喘病人一看見S就很高興的 健期的說:“挺好挺好，在咋晚夜襄一點兒都浔咳 濑”。同一病房的另一病人(與喘喘的病朱鄰近)也 插進去說: “他過去每夜咳濑很原害, 可是昨天夜 裹一點兒都沒喛嗽”。S以聽筒診了一會, 以前隨時 可琂得出來的水泡的聲㱏,完全消去了，呼吸畐調 也加强了; 病人的呼吸也恢復了正常, 也呈現愉快 的险色,在S的心裹也充滿着块樂。

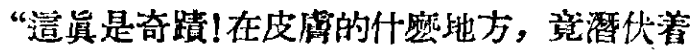
造荄不可思議的力量? 僅有一片不足火柴匣一年 大小的皮虏, 却有這樣警人的威力! 㯰送是奇跓 嗎?不,這是社會主義科學革命的勝利呀!”

S對於櫓萂聯偉大的英雄貿拉托夫，不得不起着 由裹的碽嗼。這一天的早餐, 在S的珡桌上比任何 時候都熱閳，同時有畫家，還有那位㫴喘病的妻

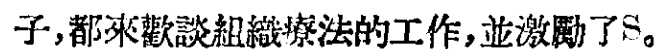

組織療法的效果,確是非常的。一位患了二年 的胸痛和牛年来一直有細微弡燒的病人, 經過一 次組織療法之後，食憼立即大增，比以前增加了二 倍。因此要求來施行手術的病人多極了, 他不得不 加以適賞的限額，每次定忿 15 人。

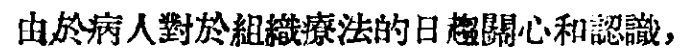
病人自己都說: “自己就是證㨜”。在受了手街之

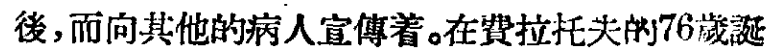
生日的那一天, 篇了紀念他,曾舉行了組䋐療法座 談會，3月6日的人民日報會發表了中央人民政府 筸發作了關於推行組織療法的指示。䜾生舆疤人 之間, 都很親密的迅速的歡欣鼓舞着這樣共同得 來的效果。病人們引起了油然而生的希望,和强烈 的涌上必治的信念, 對於抗病的心理也堅强起來 了。

由於良好成績的刺激，醫生們的工作情緒也 提高不少，關於手街和經過情况的觀察，不断的互 相討諭和研究，關答皮虚以及病况的海日變化記 錄,一天一天的積聚起來,記錄的內容也可加以整 理和分析了。於是在內科外科皮局科的熱情共同 合作,和病人的抗病心理完全結合之下, 到2月中

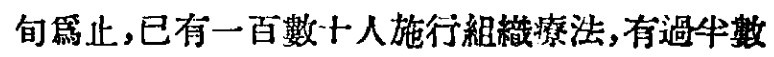
的人都得到良好的成績。

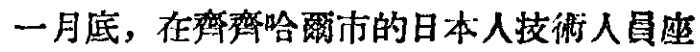

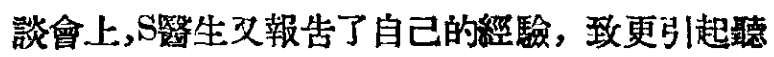

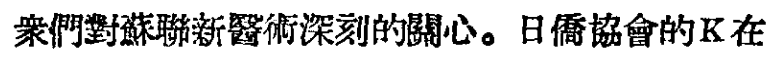
日文“新的世界”雜誌, 又特別寫了冾藏血液療法,

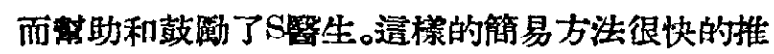
廣到醫院其他各科,都獲得了相罍成績。例如若經 過數次的注射, 數月本鼠䍊痛和胸痛的病人也全 湢了。老年人也可以恢復了視力。

$\mathrm{S}$ 又在一月牛,開始學習組織療法的注射液慗 㣁方法。可是他所製借的激鮮胎盤抽出液還沒有 達到完全透明程度而已。

2 月4日是他最難忘的一個日子，在11年前的 那一天,他管在茫南前嘎負過傷的。到了今年造一 天,他欲製成透明的抽仕液,在電嬁照明之下戱理

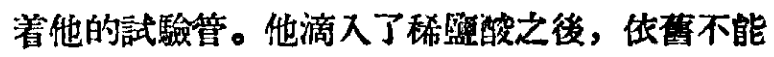
引起顯苦的況搌。他忽然想到戰場上的瀘水器來 了。“可不是嗎，我們可應用污溜池塘高的泥水加 以澄清的原理，柬應用到趛個上面吧!”他試用制 
止下涩的吸附制 (adsorbent),拿它少量來㧈入試 领管中，然後把那抽出液移入過演漏斗中，S一直 在㠜悓着漏斗的下端, 那無色的小滴, 滴答的滴答 的洨下了。在光線之下仔細的一看，逼溲液像水一 榛的透明了。8的嘫赛叫了一馨“好的”。其他的抽 出液同榜的經過如是漏斗的過流。液滴,一滴一滴 的流了下來。他拿出來了手錶,計第在一分鐘內液 滴的數目, 在電嬁光之下, 他凝視着抽出液的過

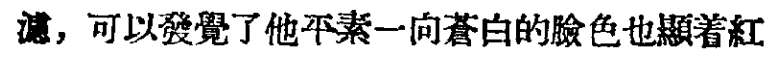
電了。

常他在做學生的時候, 想到曲頙蒸䬯器內, 那

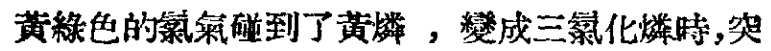
然有然然液體一滴一滴的流了出來，發出了對於

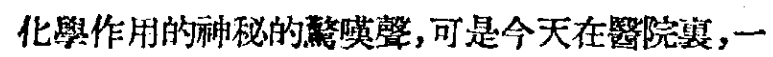
润人在深夜裏, 在登光之下, 數着流下來的液滴,

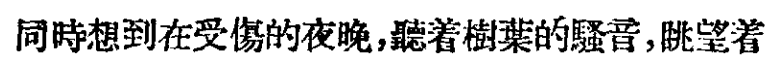
天上的星空,想到十年沿有見面的父親的老態(最 近他的父親合奇來了一張照片) 和在生活煎謷下 的凄子, 可是他想到明日的工作,造些情懷又都消 头了。

注射液的效果也相虽的好, 只要注射了2c.c, 五日以後就停止孝喘了。失服或食愍不振的人, 注
射之後也好了，因此來要求注射的人日增，連慗僧 注射液的工夫都來不及。奶市民唒院的一位痛 人，甚至已去內蒙古的一位痛人，都在事後通知 他，他們的病都已被治忞了，因此更捉高他的彆透 注射液的熱潮。第了供應本省各智院注射液的需 要量,他正在設法保定大量製造的基礎。

今天全中國各處，自接到中央人民政府的指 示以後,正在大力推行組織療法。黑龍江省衛生留 曾在3 月底與 K日起社聯合舉行㗨预工作者縕織 療法座談會, 閉會的地點就在報舘的禮堂害,對於 粗織療法的方法與效果，作過詳細的說明和討論， S醫生將植皮的手衡的詳細經過作了介紹。對中日 工作人員的䇣密疄結的康莊大道, 是有推進作用 的。更將冾藏血液療法及注射後的經驗也加以介 紹,因第組織療法效果的迅速與顛著，引起了疆衆

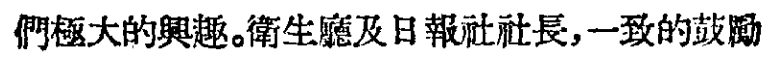

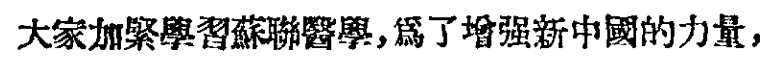
新的組織療法是必須有步驟的向前推進的。

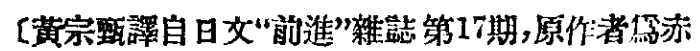
茂松，最後一段，以及其中幾可不必要的話，譯者把它显 去了。了

\section{清華大學物理系師生職工增加生産捐獻武器 以爭取抗美援朝的早日勝利}

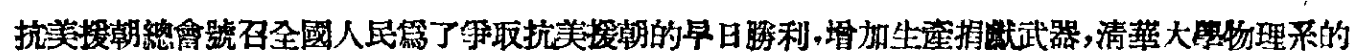

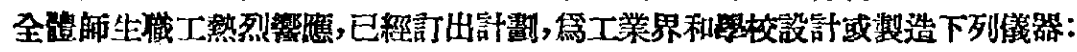

甲.各種電子管自偊控制裝置的設针

乙.電子管檥器

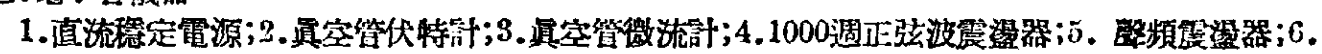
短形波震證器; 7.阻抗電橋;8.其他鈛器的欲計。

丙. 蓋格针數器整帪

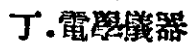

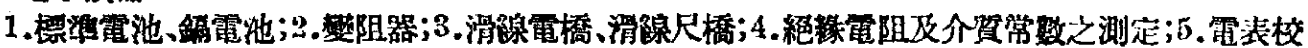
栔。

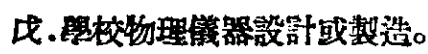

